\title{
INFLUENCE OF THERMO-CHEMICAL TREATMENT ON SURFACE LAYER PROPERTIES OF STEEL 56Si7 AND 41CrAIMO7 APPLIED IN TEXTILE INDUSTRY
}

\author{
Dariusz JEDRZEJCZYK, Stanisław PŁONKA \\ University of Bielsko-Biala, Bielsko-Biała, Poland, EU, \\ djedrzejczyk@ath.bielsko.pl, splonka@ath.bielsko.pl
}

https://doi.org/10.37904/metal.2019.727

\begin{abstract}
The paper shows the effect of thermo-chemical treatment: hardening, titanizing and boronizing of steel grade 56Si7 and 41CrAlMo7 applied for the production of yarn guides used in the textile industry. During the investigations the impact of treatment on the structure change, thickness, hardness and wear resistance of the achieved surface layers were determined. Study of the surface layer was conducted using both optical and scanning microscope. The effectiveness of carried out thermo-chemical treatment was verified in relation to the yarn guides working in industrial conditions. It has been proved that although the best results (highest hardness) was achieved after titanizing, also boronizing process guarantees sufficient wear resistance. The results of the research will be used to optimize the guides' production process including friction and economic parameters.
\end{abstract}

Keywords: Thermo-chemical treatment, wear resistance, surface layer

\section{INTRODUCTION}

The most important reasons of materials degradations that lead to the failure of different machine parts are corrosion, wear and fatigue [1]. A losses created as a result of these processes are estimated on 7-8 \% of a gross national product yearly. So, it looks that there are a lot of possibilities to improve the strategic properties of materials which influence on the machine part lifetime. The most often used method in this area is thermochemical treatment. Thermo-chemical treatment is applied mainly to iron alloys, especially steel although also similar treatment is used in production of parts made of nonferrous metals, like: molybdenum, tungsten, titanium and other [2,3]. To thermo-chemical treatment are subjected both machine parts and tools. The purpose of chemical-heat treatment is to create surface layers with increased resistance to abrasion and tribological wear, with increased corrosion and erosion resistance, often increasing the fatigue resistance or improving some physical properties of the surface [2]. Thermochemical surface engineering is dominated by carburizing, nitriding and nitrocarburizing. Boronizing, titanizing, aluminizing and other are the less often, but still frequently applied and therefore are important thermochemical surface engineering methods for special applications. The development of thermo-chemical treatment is planned in different directions. In case of nitriding, plasma nitriding and hybrid technologies with nitriding (PVD) are the most perspective. The carburising and carbonitriding need controlled atmosphere, direct quenching and low-temperature tempering. Considering the thermochemical method choice also such factors like environmental influence and final treatment cost must be taken into consideration. The mentioned parameters make boronizing less competitive. Considering that there is direct relation between hardness and tribological wear also titanizing can't be neglected. In textiles industry the special elements requirements must be fulfilled [4-6]. For example in ring spinning frames, in the throwing zone where yarn is going through the guide's eye the following functions are fulfilled: a change or maintenance of direction of the yarn course as well as creation of the appropriate tension of yarn $[7,8]$. In the tribological couple, yarn - yarn guide, the guide remains in generally stationary in relation to the yarn sliding across it. The yarn guide surface should fulfilled the following requirements: to have the relatively low friction coefficient in contact with yarn which mainly depends on the surface geometrical 
parameters achieved after mechanical working and heat treatment; to be free from electrostatic charges and "not charge" the yarn; to be sufficiently resistant to wear and accidental impact. The friction parameters affect significantly the efficiency of spinning and quality of the textile products. It is known that during the yarn slip the friction force depends on the yarn tension, the geometric structure of the yarn guide surface and physical properties of elements involved in the friction process and the external conditions under which this slippage proceeds [8]. The yarn guide working conditions require the high material abrasive resistance occurring at relatively deep layer. So, choosing the kind of thermochemical treatment the above requirements should be taken in consideration. The achieved results will be applied to multi-criterial optimization of yarn guide production process. The main aim of presented investigations was to determine the best thermochemical treatment option in relation to the achieved surface properties and unit production cost.

\section{EXPERIMENTAL}

\subsection{Sample preparation technique}

Researches were conducted in the laboratory and industrial conditions using samples taken from yarn guides of spinning machines (Figure 1). Samples were made of extruded rod of steel 56Si7, 41CrAlMo7 with diameter $\varnothing 4 \mathrm{~mm}$. A tangible result of the guide wear was the formation of the groove in its eye - Figure 1a. Thickness measurement of the wire in the guide eye was carried out after a period of operation: 2760-10400 h. In order to increase the yarn guides lifetime 12 variants of the manufacturing process have been developed and analysed, differing mainly a kind of material and, above all, a kind of chemical-heat treatment. The yarn guides made of 56Si7 steel have been subjected to the following kind of heat treatment: chrome hardening, boronizing, whereas steel 41 CrAlMo7 was nitrided and suflonitrided.

a)
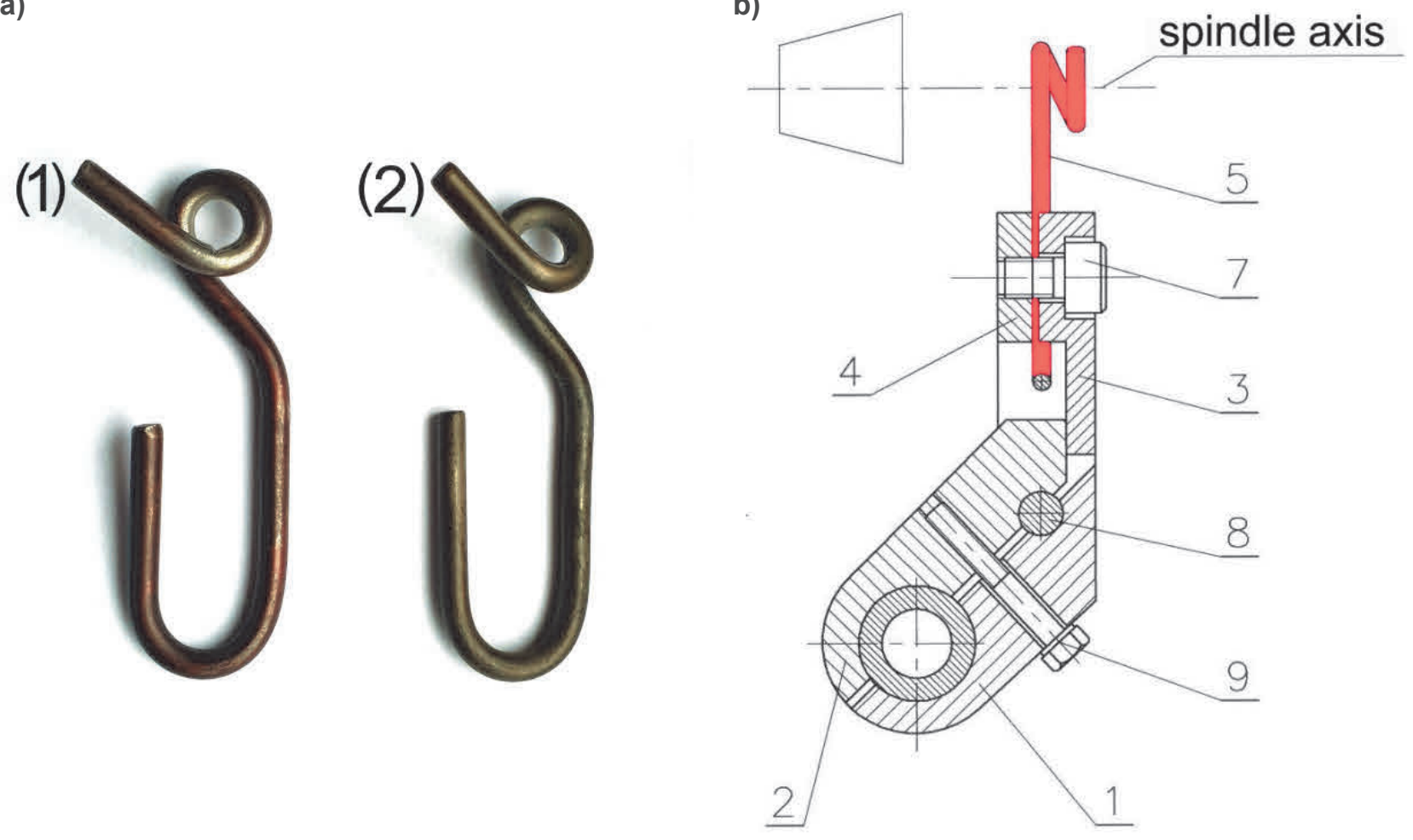

b)

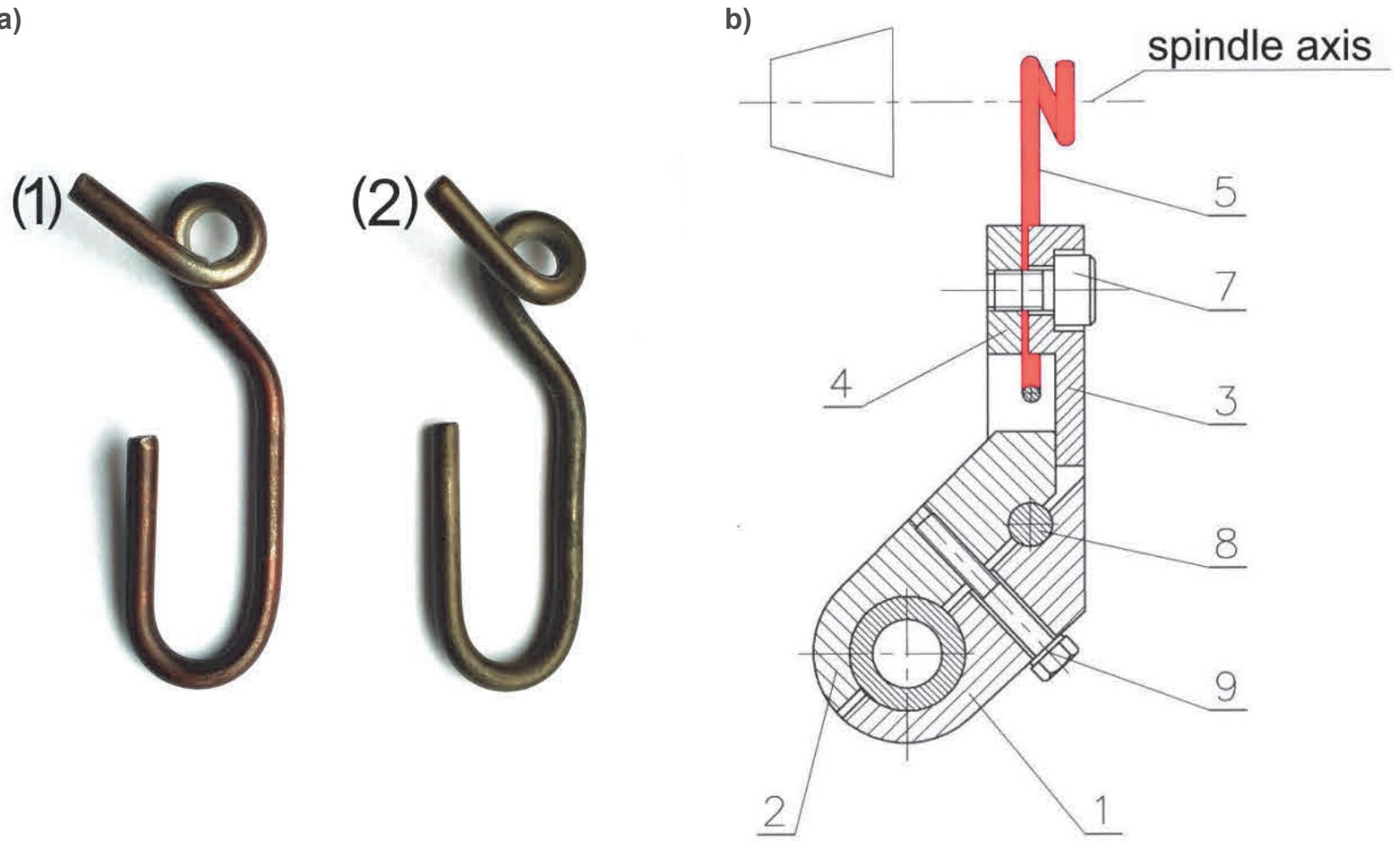

Figure 1 The appearance of the yarn guide - a and the schema of its mounting in the spinning frame - b: (1) - guide after hardening and tempering, (2) - guide after boronizing (2); 1 - the upper part of the handle, 2 the lower part of the handle, 3 - flap, 4 - nut, 5 - yarn guide, 6 - supporting pipe, 7 - bolt, 8 - pin, 9 - seizing 


\subsection{Methods of investigation}

The surface layer achieved after thermochemical treatment was evaluated on the basis of the microstructure observations conducted using the optical microscope (Axiovert $100 \mathrm{~A}$ ), the measurement of the microhardness changes at the cross section of subsurface layer of steel (Vicker's HV 0.1, Mitutoyo Micro-Vickers HM-210A device 810-401 D; Innovatest universal tester 700M). The yarn guide surface topography after thermochemical treatment and after wear out was measured by contact profile recording instrument Perthometer Concept (MAHR) with 3D software and Phase View ZeeScan optical assembly for 3D surface scanning. Values of measured hardness level and thickness of hardened subsurface layer were compiled with values of kinetic friction coefficient of the yarn in the guide eye $\mu_{\mathrm{k}}$ (friction meter R-1182, Rothschild) and cost of guide production.

\section{ANALYSIS OF RESULTS}

\subsection{Metallographic observations and micro-hardness distribution}

The impact of thermochemical treatment: hardening, chrome hardening, boronizing, titanizing, nitriding and sulfonitriding on the microhardness HV 0.1 change of the surface layer of steel $56 \mathrm{Si} 7$ and $41 \mathrm{CrAlMo} 7$ is presented in Figure 2.

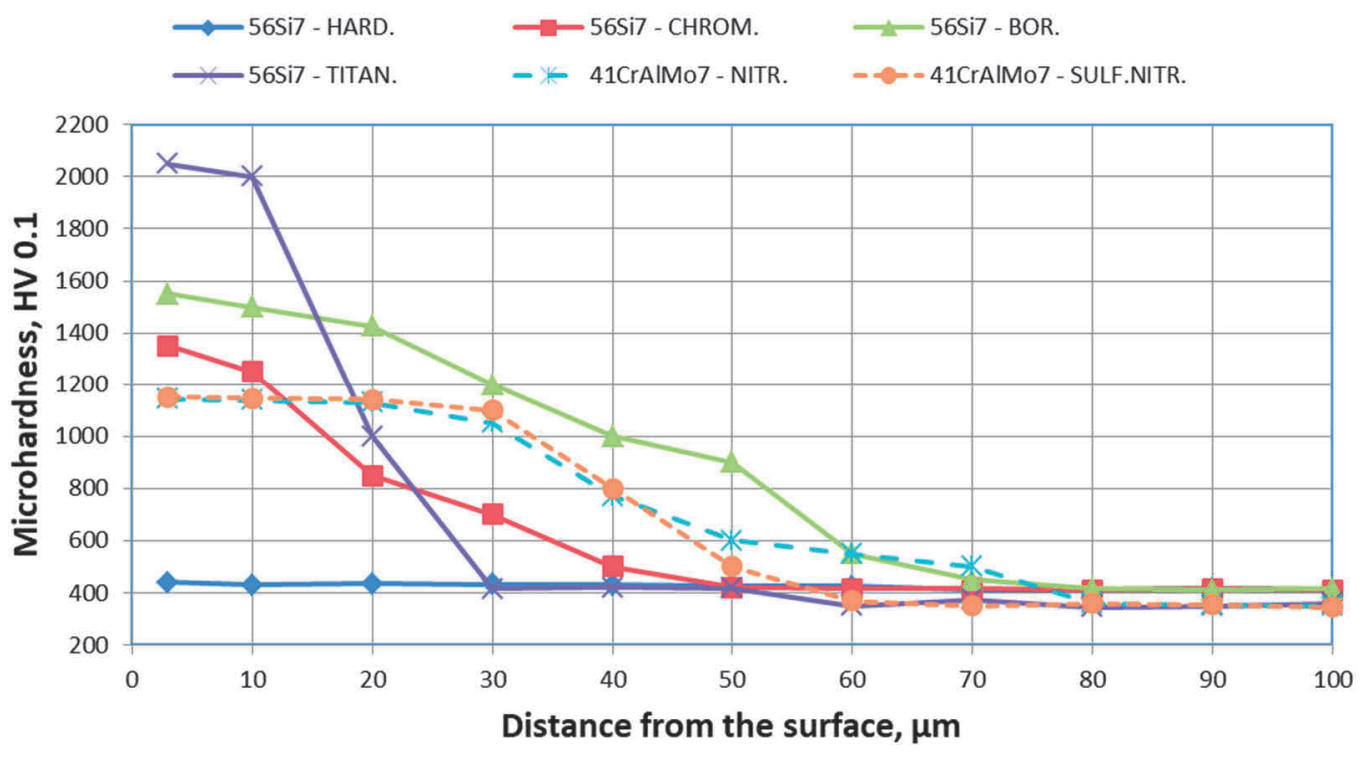

Figure 2 Microhardness distribution in surface layer after thermochemical treatment

The highest hardness values was measured after titanizing - ab. 2050 HV 0.1 ( $\left.\mu_{k}=0.240\right)$, a bit less hardness was achieved after boronizing - ab. $1550 \mathrm{HV} 0.1\left(\mu_{\mathrm{k}}=0.190\right)$. Hardness measured after chrome hardening has reached the value ab. $1350 \mathrm{HV} \mathrm{0,01}\left(\mu_{\mathrm{k}}=0.270\right)$. Results measured after sulfonitriding $\left(\mu_{\mathrm{k}}=0.174\right)$ and nitriding $\left(\mu_{\mathrm{k}}=0.175\right)$ were similar and reached level $1145 \mathrm{HV} 0.01$. The lowest hardness was measured in steel after hardening and tempering, where practically at the whole cross section hardness value was close to $400 \mathrm{HV} 0.01\left(\mu_{\mathrm{k}}=0.176\right)$. The thickest hardened layer was achieved as a result of boronizing - ab. $50 \mu \mathrm{m}$, layers after nitridizing and sulfonitridizing kept hardness at a steady level over a distance $40 \mu \mathrm{m}$. Thinnest hardened layer was achieved as a result of chrome hardening - ab. $30 \mu \mathrm{m}$ and titanizing - $20 \mu \mathrm{m}$. Thickness of hardened sublayers evaluated basing upon microhardness measurement correspond well to data determined by microscopic observations. For example Figure 3 presents the microstructure observed after boronizing and hardening. The measured thickness of surface layer after boronizing during microscopic observations (Figure $3 \mathbf{a}$ - white sublayer) is equal to $52 \mu \mathrm{m}$. The difference between determined values are 
caused by among others the difficulties in clearly defining the boundary of hardened layer that does not end abruptly but gradually changes into the core structure.

a)

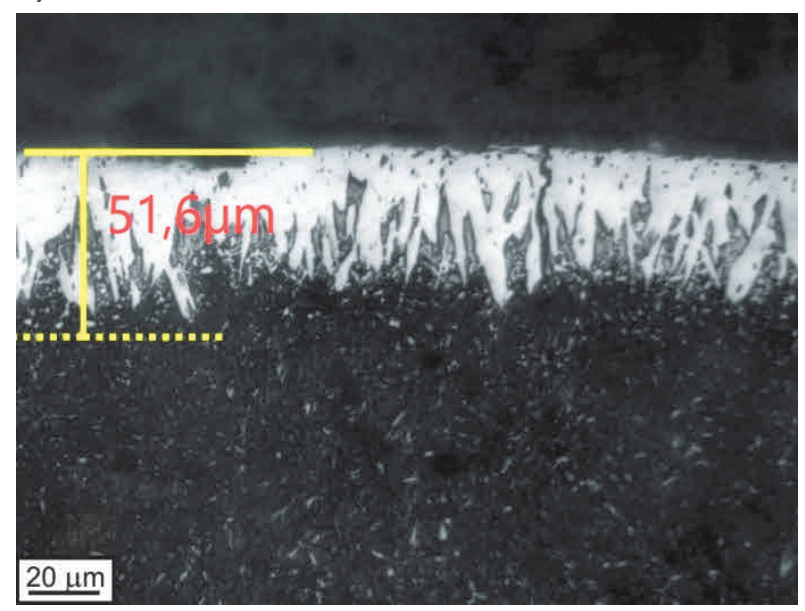

b)

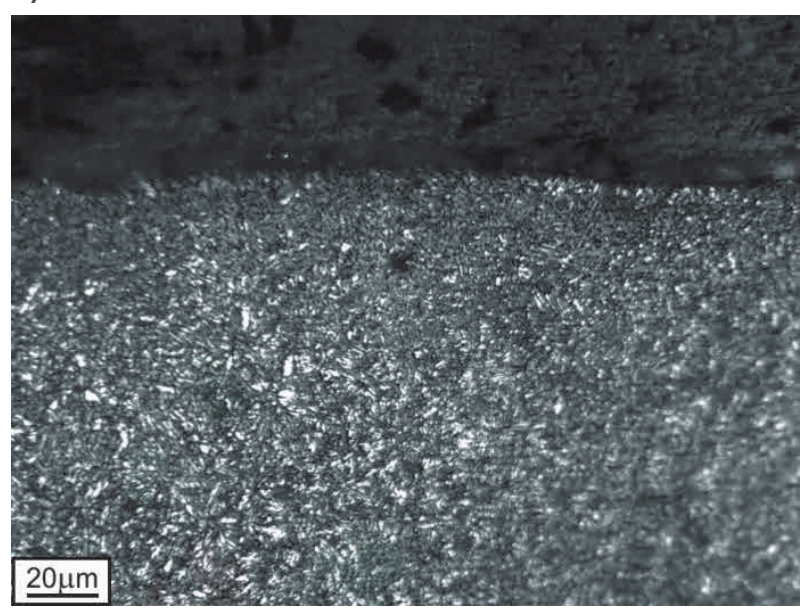

Figure 3 Microstructure of surface layer achieved after boronizing

- $a$, and hardening and tempering - b; etched with $4 \% \mathrm{HNO}_{3}$

\subsection{Analysis of guide wear}

The guide destructions caused by the cooperation with the yarn depends on the guide material properties and also on a number of other factors, such as: kind of yarn, yarn tension, speed of movement. Because the average guide wear in cooperation with yarn being the mixture : $30 \%$ polyester $+70 \%$ wool was 2.5 time higher then in cooperation with mixture: $80 \%$ argon $+20 \%$ cotton, in the reasearch more demanding mixture were used. Fibres flux, containing also foreign particles (gras, bark, straw) and contaminated by grain of dust, moving with speed $v=30 \mathrm{~m} / \mathrm{min}$ and with maximal tension up to $30 \mathrm{cN}$ and variable amplitude of the tension, causes intense wear of guide eye - forming the groove. An example of surface appearance after $8000 \mathrm{~h}$ of guide operation is presented in Figure $\mathbf{4}$ and Figure $\mathbf{5 b}$. Observation of the surface in the place of yarn friction in "macro" mode suggest that the surface is smooth and glossy (with metallic sheen), whereus the microobservations shows that on the surface the scratches exist with direction in accordance with direction of yarn movement, and the roughness in this place is equal to $S_{a}=0.15 \mu \mathrm{m}$. While the surface outside the eye is much more rough $-S_{a}=a b .2 .4 \mu \mathrm{m}$.

a)

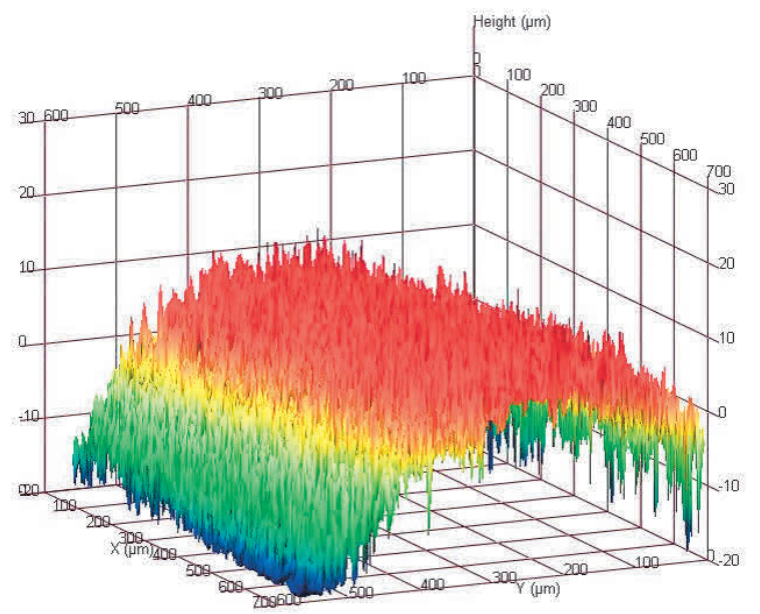

b)

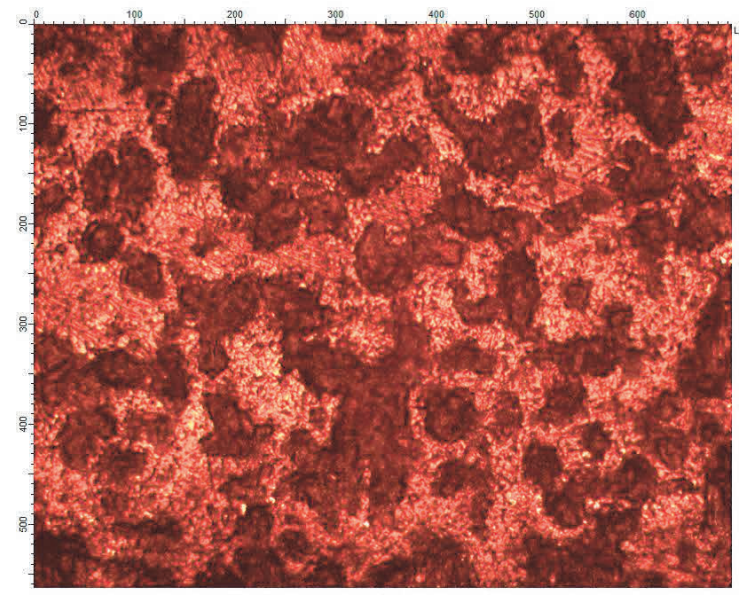

Figure 4/1 Isometric and microscopis image of the surface observed outside the guide eye - a, b and inside the groove created in guide eye - $\mathrm{c}, \mathrm{d}$ 
c)

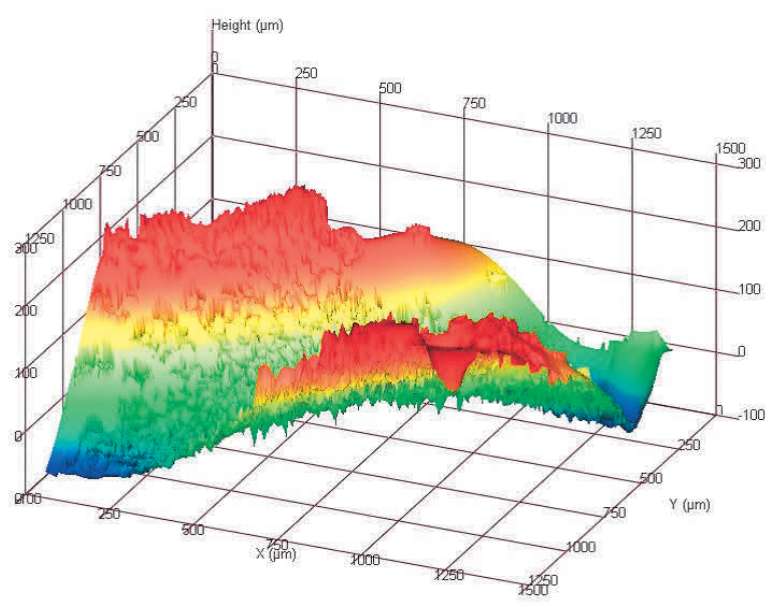

d)

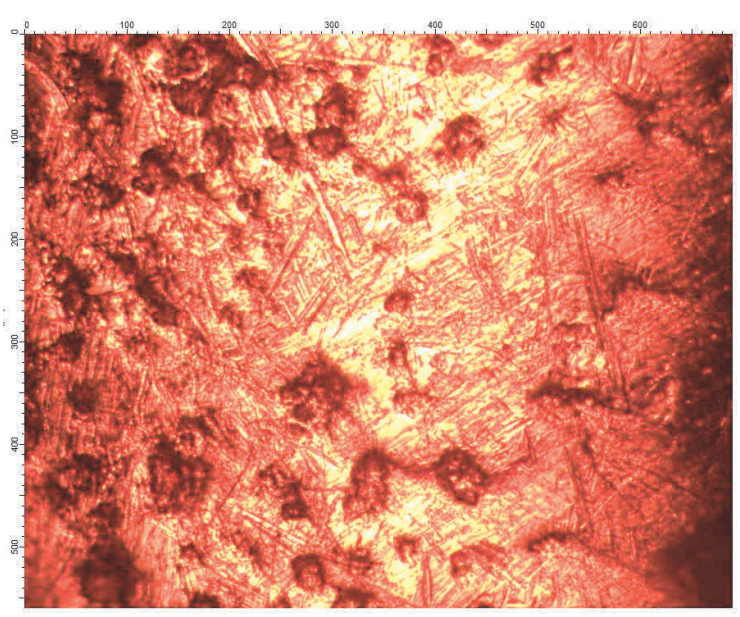

Figure 4/2 Isometric and microscopis image of the surface observed outside the guide eye - a, b and inside the groove created in guide eye - $c, d$

a)

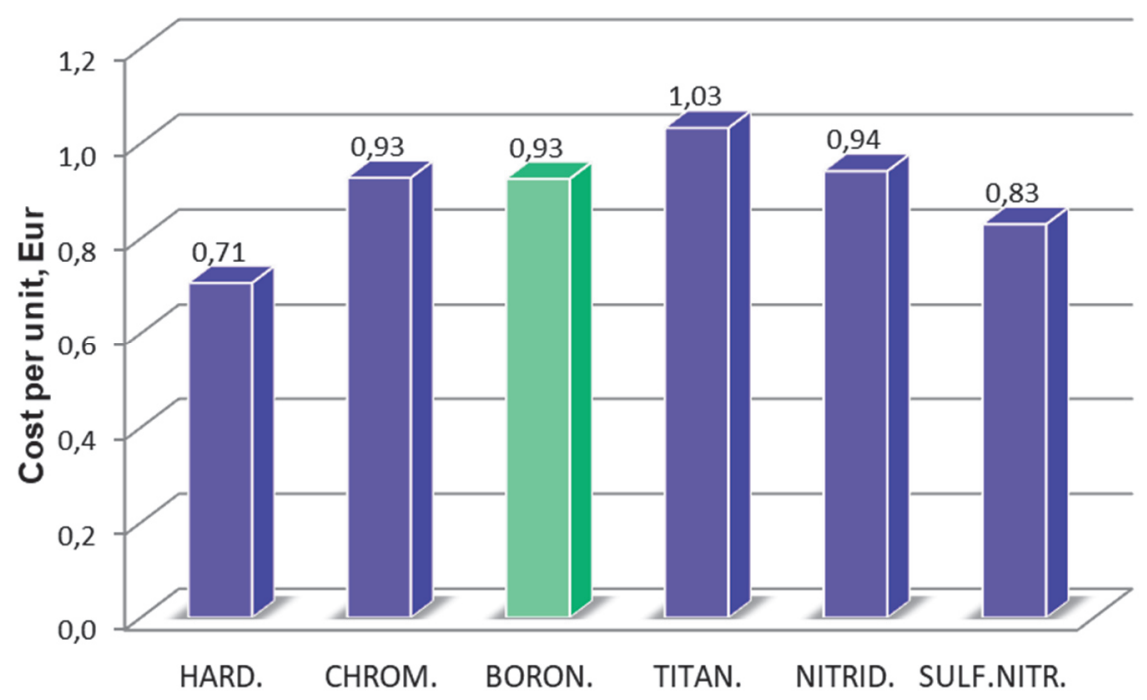

b)
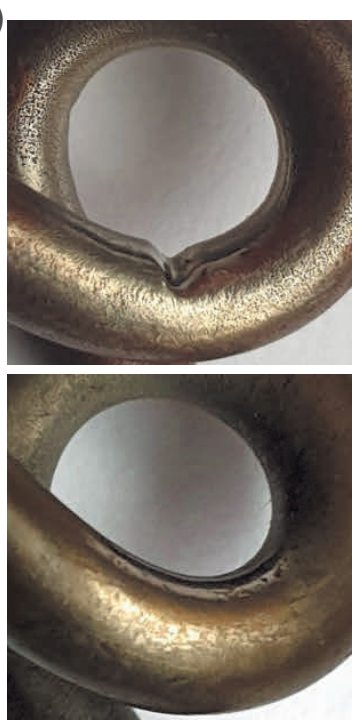

Figure 5 The comparison of the unit cost of the guide production - a and the surface appearance inside the guide eye - $b$, after hardening and tempering (upper) and after boronizing (lower)

EDS analysis of the surface layer of eye bottom didn't confirm the oxygen presence. The most likely theory seems to be that, the loss of material in guide eye is caused by the separation of micro volumes of material by friction of the solid particles in the form of grass, tree bark, straw, and often grains of dust, situated in the flux of fibres and moving together with it with speed $v=20 \div 30 \mathrm{~m} / \mathrm{min}$. These particles are pressed with a variable force to the surface of the guide as a result of the variable tension of yarn due to cyclic entry and exit from the cuts of cap and variable positioning of the spindle axis terminate in the cap during rotation. There is a high probability that the dominant importance during the yarn friction of the surface have abrasive wear. On the intensity of wear a decisive influence have two factors: yarn tension, which directly affect the value of the pressure at the place of contact of fibres flux with the surface of guide eye and the speed of yarn movement. Elana fibres being included into processed yarn, have much greater strength than the wool fibres and allows running the spinning process with greater efficiency. Increase in productivity is directly associated with higher speed of movement of the yarn. The increase in the yarn speed affects digressively on increase in the value 
of the forces (tension), and indirectly on the greater value of the contact force of yarn and the guide. The process of boronizing which ensures in surface layer of steel the hardness level ab. $1550 \mathrm{HV} 0.1$ causes that after $8000 \mathrm{~h}$ operation there is no significant changes in the topography of the surface. Although by using of

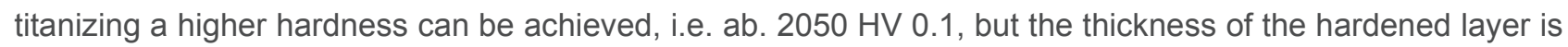
much smaller - $20 \mu \mathrm{m}$ (boronizing - $50 \mu \mathrm{m}$ ). Beside hardness level also kinetic friction coefficient value is important - there is no essential differences between boronizing $\left(\mu_{\mathrm{k}}=0.190\right)$ and nitriding $\left(\mu_{\mathrm{k}}=0.175\right)$ but both these parameters are much lower than in titanizing case $\left(\mu_{\mathrm{k}}=0.240\right)$. In addition, the unit cost of production of the titanized guide is ab. $10 \%$ higher than in the case of boronizing (Figure $5 \mathrm{a}$ ).

\section{CONCLUSIONS}

The conducted examinations enabled to express the following conclusions:

1) The wear of guides made of steel $56 \mathrm{Si} 4$ and $41 \mathrm{CrAlMo} 7$ in the course of the yarn friction is caused mainly by the abrasive process.

2) The application of the heat treatment: hardening and tempering (surface hardness ab. $400 \mathrm{HV} 0.1$ ) reduces considerably the lifetime of the yarn guides - after ab. $8000 \mathrm{~h}$ of operation in guide eye the groove with depth ab. $1.5 \mathrm{~mm}$ is observed.

3) Although the highest hardness level in surface guide layer was achieved as a result of the titanizing, because of friction conditions and economic reasons the most justified is application of boronized guides

4) Economics of yarn guides applications depends beside hardness value and thickness of hardened surface layer also on the other factors, such as: values of kinetic friction coefficient, because this parameter exerts the influence both on guide surface degradation and on number of yarn breaks and its hairiness.

\section{REFERENCES}

[1] MITTENEJER, E.J., SOMERS, M.A.J. Thermochemical surface engineering of steels. Woodhead Publishing. Woodhead Publishing Series in Metals and Surface Engineering, DTU Library No. 62, 2015. p.769.

[2] DOBRZAŃSKI, L. A., DOBRZAŃSKA-DANIKIEWICZ, A. D. Obróbka powierzchni materiałów inżynierskich, Open Access Library, Volume 5, 2011, pp. 1-480., Available from http://www.openaccesslibrary.com/index.php?id=81

[3] LANAGAN, J. Plasma Thermochemical Diffusion Treatments for Ferrous \& Non-Ferrous Alloys. The International Journal of Surface Engineering and Coatings. Vol. 69, 1991 - Issue 2., pp. 50-57, Published online: 08 May 2017]. Available from https://www.tandfonline.com/doi/pdf/10.1080/00202967.1991.11870892

[4] JEDRZEJCZYK, D., HAJDUGA, M. The influence of the kind of surface treatment on the wear of machines elements applied in the textile industry. In METAL 2013: 22rd International Conference on Metallurgy and Materials. Ostrava: TANGER, 2013, pp. 880-885.

[5] PŁONKA, S., HAJDUGA, M., JEDRZEJCZYK, D. The Wear Analysis of Steel Yarn Guide in Ring Spinning Frame. Fibres and Textiles in Eastern Europe. No. 2(61). 2007. Vol. 15, pp. 54-57

[6] PŁONKA, S., HAJDUGA, M. Effect of Surface Treatment on the Wear of Spindle-Neck Coating with a Collapse Balloon Crown. Fibres and Textiles in Eastern Europe. No. 1(97). 2013. Vol. 21, pp. 47-54.

[7] Rapal-Fadenfuhrer (Thread Guides·Guide·Fils·Guidafili·Guia-Hilas). Catalog of Paul Rauschert Gmbh \& Co KG Germany, 2006.

[8] LAWRENCE, C.A. Fundamentals of Spun Yarn Technology. CRC Press, Leeds 2003. p. 552. 